\title{
Rheology and thermal structure of the lithosphere beneath the Hawaiian Ridge inferred from gravity data and models of plate flexure
}

\author{
Alexandra Pleus, *Garrett Ito, Paul Wessel,
} AND L. NEIL FRAZER

Department of Earth Sciences, SOEST, University of

Hawai'i, Honolulu Hawai'i, USA, *gito@hawaii.edu

We examine the rheology and thermal structure of the oceanic lithosphere, expressed in situ by plate flexure beneath the Hawaiian Ridge, where volcanoes have loaded seafloor of approximately the same age, and thus where the lithosphere is expected to have had an approximately uniform agedependent thermal structure at the time of loading. Shipboard and satellite-derived gravity, as well as multibeam bathymetry data are used in models of plate flexure with curvature-dependent flexural rigidity, the strength of which is limited, in the shallow lithosphere, by brittle failure, and in the deeper lithosphere, by low-temperature plasticity (LTP). We compute relative likelihoods and posterior probabilities for four model parameters: average crustal density $\rho_{c}$, friction coefficient for brittle failure $\mu_{f}$ a pre-exponential weakening factor $F$ controlling the strength of LTP, and lithospheric geotherm age $t$. If lithosphere temperatures were as is expected for normal $(t=) 90-\mathrm{Myr}$ old seafloor at the time of volcano loading, the rheology must be significantly weaker than expected. Specifically, models with weak brittle strengths $\left(\mu_{f} \leq 0.3\right)$ show relatively high probabilities for three of the six published LTP flow laws examined. Alternatively, moderate-to-large brittle strengths $\left(\mu_{f} \geq 0.5\right)$ require all LTP flow laws to be substantially weakened with $F=10^{2}$ to $>10^{8}$ or, equivalently, activation energy reduced by $10-35 \%$. In contrast, if the lithosphere has been moderately reheated by the Hawaiian hotspot, represented by geotherms for $t=50-70 \mathrm{Myr}$, then the flow laws of Evans \& Goetze, Raterron et al., and Krancj et al. require little or no weakening. Such modest thermal rejuvenation is allowed by heatflow constraints, supported by regional mantle seismic tomography imaging as well as computed equilibrium pressure and temperature conditions of mantle xenoliths, and reconciles previously noted discrepancies between the LTP strengths of lithosphere beneath Hawaii versus that entering the Pacific subduction zones. 